\title{
Gender and Polysomnographic Profiles Findings in Obstructive Sleep Apnea Syndrome Patients Living in High Altitude
}

\author{
Marcela Concha Patiño (D) \\ Silvia Juliana Bueno Florez (iD) 2 \\ Loren Gallo iD ${ }^{3}$ \\ Paola Andrea Ortiz (iD ${ }^{2,4}$ \\ César Payán-Gómez (iD ${ }^{5}$ \\ Nicolas Molano-Gonzalez (iD) ${ }^{6}$ \\ Jesús Hernán Rodríguez (iD) 2-4,7 \\ 'Department of Neurology, Clinica \\ Nueva Rafael, Cali, Valle del Cauca, \\ Colombia; ${ }^{2}$ Department of Neurology, \\ Fundación Cardioinfantil, Bogotá, \\ Cundinamarca, Colombia; ${ }^{3}$ Department \\ of Neurology, Hospital Mederi, Bogotá, \\ Cundinamarca, Colombia; ${ }^{4}$ Grupo de \\ Neurociencias de la Universidad del \\ Rosario (NEUROS), Universidad del \\ Rosario, Bogotá, Cundinamarca, \\ Colombia; ${ }^{5}$ Department of Biology, \\ Faculty of Natural Sciences, Universidad \\ del Rosario, Bogotá, Colombia; ${ }^{6}$ Clinical \\ Research Group, School of Medicine and \\ Health Sciences, Universidad del Rosario, \\ Bogotá, Cundinamarca, Colombia; \\ ${ }^{7}$ Neurology department, School of \\ Medicine and Health Sciences, Bogotá, \\ Cundinamarca, Colombia
}

Purpose: Obstructive sleep apnea (OSA) is a common sleep disorder which prevalence is $22 \%$ in men and $17 \%$ in women. It is well described that females presented different clinical and polysomnographic characteristics compared with men. Those studies were performed in plain areas. We described the analysis by gender and clinical profiles of a sample of patients with diagnostic of OSA and living at high altitude.

Patients and Methods: It is an observational study that describes differences between clinical and polysomnographic characteristics by gender in patients with OSA. Additionally, an unsupervised cluster algorithm was used to find groups of patients with similar clinical and polysomnographic characteristics.

Results: We included 709 patients, 51.6\% were females and 48.3\% were males with mean age of 64 and 62 years old, respectively, in which $90.97 \%$ presented OSA. Men presented a higher apnea and hypopnea index than women $(\mathrm{p}=0.002)$, besides presented more sleep polysomnographic alterations. Meanwhile, women evidenced better sleep quality based on parameters. Additionally, in the sample of patients, we found four separated clinical profiles characterized mainly by differences in the severity of polysomnographic parameters.

Conclusion: The patients were more obese, older, and had lower $\mathrm{SpO}_{2}$ values than most of those previously reported. Men had greater severity in most of the parameters measured by polysomnography. Polysomnographic variables were different both in the OSA patient profiles and in the gender comparison. However, the REM sleep apnea hypopnea index did not differ between sexes, indicating the importance of this variable in the evaluation of OSA severity in women. In contrast to previous reports, clinical and demographic characteristics showed few differences in both analyses. This result suggests that the behavior of OSA at high altitudes may have particularities with respect to low altitudes.

Keywords: sleep-disordered breathing, cluster analysis, altitude, gender identity, sleep monitoring

\section{Introduction}

Obstructive Sleep Apnea (OSA) is a common sleep disorder characterized by upper airway collapse which halts ventilation, leading to hypoxia, hypercapnia or sleep disruption. ${ }^{1}$ The prevalence of OSA in the general population is $22 \%$ in men and $17 \%$ in women, ${ }^{2}$ with some changes in the prevalence according to age, between 30 and 49 years the prevalence is $3 \%$ in women and $10 \%$ in men, between 50 and 70 years it is $9 \%$ and $17 \%$, respectively. ${ }^{1}$
Correspondence: Nicolas Molano-Gonzalez Clinical Research Group, School of Medicine and Health Sciences, Universidad del Rosario, Carrera 23 \# 63a-40, Bogotá D.C, III221, Colombia

$\mathrm{Tel}+(57 \mathrm{I}) 2970200$ Ext. 3400

Email nicolas.molano@urosario.edu.co 
There is evidence that OSA is an independent risk factor for cardiovascular diseases including hypertension, stroke, heart failure, coronary heart disease, and arrhythmias. ${ }^{3}$ Additionally, in hospitalized patients with decompensated heart failure, mortality rates are higher in patients with OSA. ${ }^{4,5}$ Furthermore, studies have assessed OSA as a probable risk factor for developing metabolic diseases like diabetes mellitus type 2, glucose intolerance, and metabolic syndrome. ${ }^{6,7}$ Likewise, patients with cardiovascular and metabolic comorbidities have a higher incidence of OSA.

The majority of studies have included more men than women $^{8-12}$ and reported a higher OSA prevalence in males. Females had different polysomnographic (PSG) parameters than men, such as a lower Apnea Hypopnea Index (AHI), ${ }^{13,14}$ along with a different clinical presentation. The most common symptoms in females are nocturnal choking, morning headache, fatigue, insomnia, impaired memory, mood disorders, reflux, nocturia, and enuresis. ${ }^{12,15}$ The prevalence of OSA increases through life in both genders and is influenced by the presence of comorbidities such as obesity; however, women have less severe symptoms at all ages compared to men. ${ }^{16}$ The heterogeneity in the clinical presentation of OSA leads to variations in the results of sleep questionnaires by gender and at different ages. ${ }^{13,17-19}$

On the other hand, in high altitude places, hypoxia is a common consequence of reduced oxygen partial pressure which leads to changes in oxygen saturation in blood, that is exacerbated during sleep. ${ }^{20}$ It had been reported that high altitude environments and patients with OSA had functional neurological changes compared to healthy voluntaries. $^{21}$ Therefore, it is important to study how exposure to chronic high altitude affects patients with OSA and how the age, sex, and other factors impact the patients.

Previous studies evidenced that OSA patients present different profiles, based on their symptoms, clinical characteristics, and disease severity, nevertheless those articles analyzed populations that differ in many ways such as age, symptoms, sociodemographic, and clinical characteristics. ${ }^{22-27}$ However, none of those articles reported clusters from patients exposed to high altitude, which may represent an important modifying factor of OSA phenotypes.

In this context, an observational study was conducted to evaluate the potential differences in clinical variables and PSG characteristics by gender in a sample of patients diagnosed with OSA and living in a high altitude city
(2600 meters above sea level). Additionally, in this specific group of patients, a profile analysis was performed in order to increase the comprehension of OSA phenotypes at high altitude.

\section{Patients and Methods Subjects}

This observational study included 709 patients who were evaluated retrospectively in the neurophysiology laboratory at Méderi Hospital, a tertiary care public hospital in Bogotá, Colombia, South America. Bogotá is located at 2600 meters above sea level. The information was retrieved from January 2011 to September 2019. The patients were referred to the neurophysiology laboratory from hospitalization and from external consults due to a clinical suspicion of OSA based on the Epworth scale.

Demographic data were collected, including age, gender, body mass index (BMI), and medical history (hypertension, diabetes mellitus type 2, chronic obstructive pulmonary disease [COPD], coronary disease, stroke, dyslipidemia, atrial fibrillation, and rheumatoid arthritis).

\section{Sleep Questionnaire}

The Epworth scale, which was applied to all the study participants, has been recommended by the Colombian healthcare system; a systematic review reported that it had good internal consistency ${ }^{28}$ and another metaanalysis reported a high specificity for different degrees of disease severity. ${ }^{29}$ This questionnaire consists of eight questions, each one covering the subject's probability of falling asleep in a situation common in daily life. Thus, the score for each item on the scale measures a sleep propensity, and the sum of the score measures the subject's average sleepiness. A higher score indicates greater subjective sleepiness.

\section{Polysomnography}

Polysomnography was performed using a Cadwell ${ }^{\circledR}$ Easy III polysomnography machine, recording all the patient's sleep hours in a controlled environment, allowing the quantity and quality of sleep, apneic and non-apneic events, cardiac repercussions, and neurophysiological repercussions to be observed. To consider the study valid for interpretation, more than 6.5 hours had to have been recorded, of which no fewer than 180 minutes had to have been effective sleep. During the procedure, electroencephalographic monitoring was performed and sensors on 
fingers or toes, bands, flow sensors, and pulse oximetry were used to record the different variables. The PSG had 10 channels, with the ability to record different variables simultaneously as follows: electroencephalogram 1-2 channels, electrooculogram1-2 channels, EMG of chin muscle surfaces 1 channel, ECG 1 channel, EMG of anterior tibial muscle surfaces 1 channel, air flow sensor 1 channel, thoracoabdominal respiratory effort sensors 2 channels, and pulse oximetry 1 channel; along with the measurement of oronasal flow and thermal sensors of $\mathrm{Co} 2$ flow (capnography). Respiratory effort was measured by respiratory effort bands. ${ }^{30}$

The PSG data collected included total sleep time, nonrapid eye movement (REM) latency, \% of non-REM sleep during mild sleep, \% of non-REM sleep during deep sleep, $\%$ of non-REM sleep during deeper sleep, sleep cycles, \% sleep efficacy, index of micro-awakenings per hour, index of micro-awakenings per respiratory event, number of periodic leg movements per hour, total AHI, AHI during non-REM sleep, AHI during REM sleep, AHI in the supine position, positional OSA per hour, central apnea, obstructive apnea, mixed apnea, hypopneas, saturation level, and $\%$ saturation $<90 \%$ during sleep.

\section{OSA Diagnosis}

A diagnosis of OSA was made based on the American Academy of Sleep Medicine's (AASM's) International Classification of Sleep Disorders-Third Edition, according to which patients must have either signs/symptoms (eg, associated sleepiness, fatigue, insomnia, snoring, subjective nocturnal respiratory disturbances, or observed apnea) or associated medical or psychiatric disorders (ie, hypertension, coronary artery disease, atrial fibrillation, congestive heart failure, stroke, diabetes, cognitive dysfunction, or mood disorders) coupled with five or more predominantly obstructive respiratory events (obstructive and mixed apneas, hypopneas, or respiratory effort-related arousals, as defined by the AASM scoring manual) per hour of sleep during PSG. Alternatively, 15 or more obstructive respiratory events per hour satisfy the criteria, even in the absence of associated symptoms or disorders. $^{31-33}$

\section{Data Analysis}

Qualitative variables were reported as frequencies and percentages, and quantitative variables median and interquartile range since all variables presented a non-normal distribution based on Shapiro Wilk test.
In order to characterize patients' clinical profile, a mixed cluster analysis was done following the methodology proposed by Lebart et al $1995^{34}$ In short, this is a three-step approach: 1) data of variable nature (qualitative and quantitative) are represented in a new coordinate system using factorial analysis for mixed data. This achieves a homogenous representation of the data set in numerical variables called principal components. 2) Using this new representation of the data, a hierarchical cluster analysis using the ward method is used to construct a hierarchical cluster tree and the optimal number of clusters is determined by means of the between-cluster inertia gain criterion. Product of this step, a first set of clusters of patients is determined. 3) Finally, the cluster membership for each individual is consolidated using a k-means algorithm on the centroids of each cluster. In the end, a categorical variable in which each individual is assigned to one and only one of the clusters derived is obtained. Afterwards, a description of each cluster is developed by studying the distribution of each of the original variables used for clustering in each of the derived groups. This determines the composition and relation of the original variables and the clusters as well as the clinical interpretation of this clusters.

The variables used to build the clusters (profiles) were sociodemographic and clinical. Age, gender, weight, height, BMI, medical history (hypertension, diabetes mellitus type 2, chronic obstructive pulmonary disease [COPD], coronary disease, stroke, dyslipidemia, atrial fibrillation, rheumatoid arthritis) and ESS besides PSG findings like total sleep time, non-rapid eye movement (REM) latency, \% of non-REM sleep during mild sleep, $\%$ of non-REM sleep during deep sleep, \% of non-REM sleep during deeper sleep, sleep cycles, \% sleep efficacy, index of micro-awakenings per hour, index of microawakenings per respiratory event, number of periodic leg movements per hour, total AHI, AHI during non-REM sleep, AHI during REM sleep, AHI in the supine position, positional OSA per hour, central apnea, obstructive apnea, mixed apnea, hypopneas, saturation level, and \% saturation $<90 \%$ during sleep.

Bivariate analysis was employed to evaluate gender associations between other clinical and demographic variables, as well as to characterize the clusters characteristics in terms of the original variables used to build them. We used the Kruskal-Wallis test to assess the relationship between gender and the clusters with continuous variables, for those we report the median and interquartile range for 
each continuous variable at each gender and cluster. Similarly, the chi-square test for independence was used to assess the same relations for qualitative variables, in this case, conditional proportions are reported for each gender and cluster.

Finally, since there were several hypothesis tests done in this study, we adjusted the p-values obtained using the false discovery rate approach proposed by Benjamini and Hochberg. ${ }^{35}$ All statistical analyses were done using software $\mathrm{R}$ version 4.0.2. ${ }^{36}$

\section{Data Availability}

Data use in this study are available from Dryad (https:// datadryad.org/stash/). Anonymous data will be shared by request from any qualified investigator (https://datadryad. org/s t a s h/s hare/h c h O-jx 78 Z s fIDqOPE a MhHwEpPHN8ANoMGgwiRmwiw).

This study was performed according to Declaration of Helsinki and Ministry of Health's resolution 008430 of 1993 ("Scientific, technical and administrative norms for health research") and was approved by the ethics committee of Rosario University, besides all patients singed a patient consent form at hospital admission for data management and research purposes.

\section{Results}

\section{Demographic and Clinical Characteristics of Patients in the Study}

A total of 709 subjects (366 women and 343 men) were evaluated in Méderi Hospital's neurophysiology laboratory from January 2011 to September 2019. Most of the patients were referred from hospitalization (513 [79.53\%]); the remaining subjects were referred from external consultation (132 [20.47\%]). We collected the demographic, clinical, and PSG data from all of them. Women had a mean age (standard deviation) of 64.03 (14.26) years, and men were younger, with a mean age of $62( \pm 12.83)(\mathrm{p}=0.006)$. The BMI was similar in women and men, at $30.4( \pm 7.93) \mathrm{kg} / \mathrm{m}^{2}$ vs $31( \pm 7.68)$, respectively $(\mathrm{p}=0.909)$.

After the PSG, and according to the AASM International Classification of Sleep Disorders-Third Edition diagnostic criteria, 645 subjects $(90.97 \%$ of the total sample) were diagnosed with OSA. There were 316 (49\%) men with a median age $62(53-71)$ years and 329 (51\%) women with a median age of 65 (58-74). The median BMI in men was 31.1 (27-35.6) vs 30.4 (26.1-
Table I Demographic Characteristics and Comorbidities of Patients with Obstructive Sleep Apnea

\begin{tabular}{|c|c|c|c|}
\hline & $\begin{array}{l}\text { Females } \\
\text { N (\%) Median } \\
\text { (IR) }\end{array}$ & $\begin{array}{l}\text { Males N (\%) } \\
\text { Median (IR) }\end{array}$ & Adjust $\mathbf{P}$ \\
\hline Total & 329 & 316 & \\
\hline Age* & 65 (58-74) & $62(53-7 I)$ & $0.004 I^{* *}$ \\
\hline Height* & $157(151-164.5)$ & $166(|60-17|)$ & $4.23 \times 10^{-6 * *}$ \\
\hline Body mass index* & $30.4(26.1-36.2)$ & $31.1(27-35.6)$ & 0.8076 \\
\hline $\begin{array}{l}\text { Diabetes mellitus } \\
\text { type } 2\end{array}$ & $67(20.36)$ & $59(18.67)$ & 0.8007 \\
\hline $\begin{array}{l}\text { Chronic obstructive } \\
\text { pulmonary disease }\end{array}$ & $80(24.32)$ & $68(21.52)$ & 0.6036 \\
\hline Hypertension & $167(50.76)$ & $136(43.04)$ & 0.0978 \\
\hline $\begin{array}{l}\text { Coronary artery } \\
\text { disease }\end{array}$ & $51(15.5)$ & $47(14.87)$ & 0.9105 \\
\hline Dyslipidemia & $26(7.9)$ & 44 (13.92) & 0.0425 \\
\hline Stroke & $13(3.95)$ & $17(5.38)$ & 0.6367 \\
\hline Atrial fibrillation & $9(2.73)$ & II (3.48) & 0.8076 \\
\hline Epworth scale & & & 0.4650 \\
\hline $\begin{array}{l}\text { Normal sleep } \\
(0-5)\end{array}$ & 74 (22.49) & $56(17.72)$ & \\
\hline $\begin{array}{l}\text { Average sleepiness } \\
(6-8)\end{array}$ & $35(10.64)$ & 37 (11.7I) & \\
\hline $\begin{array}{l}\text { Abnormal } \\
\text { somnolence } \\
(9-24)\end{array}$ & $220(66.87)$ & $223(70.57)$ & \\
\hline
\end{tabular}

Notes: *Values are expressed as the median and interquartile range. Comorbidities and Epworth scale are expressed as the number (percentage) of individuals with the disease/result in the Epworth scale. ** Statistical significant values $\mathrm{P}<0.05$.

36.2) in women $(\mathrm{p}=0.807)$ (Table 1).The values obtained on the Epworth scale were similar for both sexes: 223 (70.57\%) men and 220 (66.87\%) women reported abnormal somnolence, with no significant statistical difference according to gender $(\mathrm{p}=0.465)$. Regarding comorbidities, there were no statistical differences between men and women in almost all the clinical diagnoses; only the prevalence of dyslipidemia was statistically different, with a higher frequency in males $(\mathrm{p}=0.042)$ (Table 1).

\section{Sleep Parameters and Gender}

Two of the three OSA severity indicators, total AHI and supine AHI, were statistically significantly different, with higher values in men compared to women. The other OSA severity indicator, REM AHI, was not different between the sexes $(\mathrm{p}=0.808)$.

Several PSG parameters of poor sleep quality were statistically significantly different between the sexes. Micro-awakenings during sleep associated with respiratory events $(p=0.004)$, the periodic limb movements index 
Table 2 Polysomnographic Sleep Parameters of Females and Males

\begin{tabular}{|c|c|c|c|}
\hline & Females Median (IR) & Males Median (IR) & Adjust $\mathbf{P}$ \\
\hline Total Apnea hypopnea index (AHI) (events/h) & $14.4(8.4-24)$ & $18.6(9-35.9)$ & $0.0072 * *$ \\
\hline REM AHI (events/h) & $12.8(3.8-26)$ & $13.15(1.92-29.32)$ & 0.8076 \\
\hline Supine AHI (events/h) & $13(6-25.85)$ & $19(7-41.65)$ & $0.0048 * *$ \\
\hline Total sleep time $(\mathrm{min})$ & $425(344-553)$ & $391(321.75-499.75)$ & $0.0119 * *$ \\
\hline Sleep efficiency (\%) & $84(72-93)$ & $82(69-90)$ & $0.0119 * *$ \\
\hline REM sleep latency (min) & $135(73-225)$ & $\mid 28(6|-2| 4)$ & 0.3032 \\
\hline N3 sleep (\%) & $6(0-10)$ & $3(0-8)$ & $0.0011 * *$ \\
\hline REM sleep ${ }^{* *}(\%)$ & $12(6-16)$ & $10(5-15)$ & $0.047 I^{* *}$ \\
\hline Sleep cycle (\%) & $3(2-4)$ & $3(2-4)$ & 0.0978 \\
\hline Micro-awakenings during sleep associated with respiratory events (events/h) & $8(3-19)$ & $12(5-25)$ & $0.0041^{* *}$ \\
\hline Periodic Limb Movements Index (events/h) & $0(0-1)$ & $0(0-2)$ & $0.0403 * *$ \\
\hline Central apnea (events) & $0(0-3)$ & $\mathrm{I}(0-7.25)$ & 0.0922 \\
\hline Obstructive apnea (events) & $13(3-44)$ & $19.5(5-54)$ & $0.0258 * *$ \\
\hline Mixed apnea (events) & $0(0-2)$ & $0(0-4)$ & $0.0068 * *$ \\
\hline Mean $\mathrm{SpO}_{2}(\%)$ & $86(80-88)$ & $86(80.75-89)$ & 0.5358 \\
\hline Sleep time with $\mathrm{SpO}_{2}<90 \%$ (\%) & $59(26-91)$ & $61.5(26-90)$ & 0.8520 \\
\hline
\end{tabular}

Note: Values are expressed as the median and interquartile range. $* *$ Statistical significant values $\mathrm{P}<0.05$.

$(p=0.040)$, central apneic events $(p=0.092)$, obstructive apnea $(\mathrm{p}=0.026)$, and mixed apnea $(\mathrm{p}<0.007)$ were higher in males compared to females (Table 2).Likewise, good sleep quality parameters were higher and statistically significant in female compared to male; for example, total sleep time $(p=0.012)$, sleep efficiency $(p=0.012)$, and percentage of REM sleep ( $\mathrm{p}=0.047$ ) (Table 2).

The total AHI was regrouped in three categories according to the number of apnea or hypopnea events per hour. Patients with 30 or more episodes of apnea or hypopnea were classified as severe. When the AHI was between 15 and 29 it was classified as moderate, and patients with 4 to 14 events were classified as mild. Similarly, with the presence of worse sleep parameters in males compared to females, the total AHI categories were different by sex. There were more males (29.43\%) with severe total AHI than females $(16.63 \%)$ and more females

Table 3 Total AHI Categories of Patients with Obstructive Sleep Apnea

\begin{tabular}{|l|l|l|l|}
\hline & $\begin{array}{l}\text { Females } \\
\text { N (\%) }\end{array}$ & $\begin{array}{l}\text { Males } \\
\text { N (\%) }\end{array}$ & $\begin{array}{l}\text { Adjust } \\
\mathbf{P}\end{array}$ \\
\hline $\begin{array}{l}\text { Total AHI categories } \\
\text { Mild (5-14) }\end{array}$ & $175(53.19)$ & $139(43.99)$ & $0.0068^{* *}$ \\
Moderate (15-29) & $96(29.18)$ & $84(26.58)$ & \\
Severe ( $\geq 30)$ & $58(16.63)$ & $93(29.43)$ & \\
\hline
\end{tabular}

Note: Values are expressed as the number (percentage) of individuals into the categories. ** Statistical significant values $\mathrm{P}<0.05$.
(53.19\%) with mild total AHI than males (43.99\%) (Table 3).

\section{Profiles Analysis of a Sample of OSA Patients Living in High Altitude}

The complete group of patients diagnosed with OSA were analyzed with a profile analysis approximation. Using the method proposed by Lebart ${ }^{34}$ it was found that the best description of the sample studied was obtained by separating it into 4 profiles. Tables 4 and 5 show the variables used to calculate the profiles and their distribution across each profile.

Profile 1 consisted exclusively of patients who did not enter REM at any time during the study (NoREM profile). Profile 2 comprises mainly of patients with normal sleep efficiency (Normal sleep efficiency profile). Profile 3 contains mainly of patients with abnormal sleep efficiency (Abnormal sleep efficiency profile). Finally, profile 4 includes patients with more severe AHI (Severe AHI profile).

Each of the profiles had polysomnographic characteristics that differentiated them from the other profiles. In profile 2, only the $10.2 \%$ of the patients had abnormal sleep efficiency, conversely, $99.2 \%$ of the patients in profile 3 had abnormal sleep efficiency. Fifty-six percent of patients in profile 1 had abnormal sleep efficiency, profile 4 had a similar proportion (59.5\%) to profile 1 (Table 4).

The global AHI was within the severe classification (greater than 30) for $98.4 \%$ of patients in profile 4 , for 
Table 4 Categorical Variables Used in the Construction of the Profiles of Patients and the Distribution Across Each Profile

\begin{tabular}{|c|c|c|c|c|c|}
\hline Variable & Profile I N (\%) & Profile 2 N (\%) & Profile 3 N (\%) & Profile 4 N (\%) & Adjust $\mathbf{P}$ \\
\hline Total & 46 & 225 & 246 & 126 & \\
\hline Female & $20(43.48)$ & $134(59.56)$ & $126(5 \mid .22)$ & $47(37.3)$ & $0.0010 * *$ \\
\hline Diabetes mellitus type 2 & $9(19.57)$ & $37(16.44)$ & $57(23.17)$ & $22(17.46)$ & 0.3178 \\
\hline Chronic obstructive pulmonary disease & $15(32.61)$ & $46(20.44)$ & $77(31.30)$ & $10(7.94)$ & $4.8 \times 10^{-6 * *}$ \\
\hline Hypertension & $24(52.17)$ & $91(40.44)$ & $138(56.1)$ & $48(38.1)$ & $0.0012^{* *}$ \\
\hline Coronary artery disease & $6(13.40)$ & $36(16.00)$ & $37(15.04)$ & $18(14.29)$ & 0.9484 \\
\hline Dyslipidemia & $I(2.2)$ & $15(6.67)$ & $37(15.04)$ & $16(12.7)$ & $0.0068 * *$ \\
\hline Stroke & $2(4.35)$ & $10(4.44)$ & $15(6.10)$ & $3(2.38)$ & 0.4824 \\
\hline Atrial fibrillation & $\mathrm{I}(2.17)$ & $7(3.11)$ & $9(3.66)$ & $3(2.38)$ & 0.9280 \\
\hline Epworth Scale & & & & & 0.0985 \\
\hline Abnormal somnolence & $32(69.57)$ & $166(73.78)$ & $158(64.23)$ & $86(68.25)$ & \\
\hline Moderate somnolence & $7(15.22)$ & $23(10.22)$ & $24(9.76)$ & $18(14.29)$ & \\
\hline Normal somnolence & $7(15.22)$ & $36(16)$ & $64(26.02)$ & $22(17.46)$ & \\
\hline Positional OSA & $26(56.52)$ & $119(52.89)$ & $152(61.79)$ & $98(77.78)$ & $7.82 \times 10^{-5 * *}$ \\
\hline Global AHI & & & & & $0.0001 * *$ \\
\hline $5-14$ & $20(43.48)$ & $|4|(62.67)$ & $153(62.2)$ & $0(0)$ & \\
\hline $15-29$ & $12(26.09)$ & $79(35.11)$ & $86(34.96)$ & $2(1.59)$ & \\
\hline$\geq 30$ & 14(30.43) & $5(2.22)$ & $7(2.85)$ & $124(98.4 \mid)$ & \\
\hline REM latency & & & & & $1.12 \times 10^{-134 * *}$ \\
\hline$>120$ minutes & $0(0)$ & $8(3.55)$ & $16(6.50)$ & $6(4.76)$ & \\
\hline No REM latency & $46(100)$ & $0(0)$ & $0(0)$ & $0(0)$ & \\
\hline Sleep efficiency $<85 \%$ & $26(56.52)$ & $23(10.22)$ & $244(99.19)$ & $75(59.52)$ & $5.85 \times 10^{-81 * *}$ \\
\hline Central apnea $>5$ events $/ \mathrm{h}$ & I4(30.43) & $55(24.44)$ & $34(13.82)$ & $55(43.65)$ & $1.50 \times 10^{-8^{* *}}$ \\
\hline
\end{tabular}

Note: Values are expressed as the number (percentage) of individuals into the categories or with the condition. $* *$ Statistical significant values $\mathrm{P}<0.05$.

$30.4 \%$ of people in profile 1 , and for less than $3 \%$ for profiles 2 and 3 (Table 4).

The percentage of patients with more than 5 episodes of obstructive apnea was higher in profile $4(46.5 \%)$, followed by profile $1(17.5 \%)$. This parameter was similar for profiles 2 and $3(12 \%$ and $11.5 \%$, respectively) (Table 5).

The proportion of sleep in which patients presented oxygen saturation below $90 \%$ was the highest for profile $1(79.5 \%)$, followed by profile $4(73.5 \%)$ with equally abnormal, but lower, proportions for profiles 2 and 3 (60\% and 50\%, respectively) (Table 5).

Now, regarding gender, the highest proportion of women was in profile $2(60 \%)$, the profile with normal sleep efficiency. The lowest proportion of women (37\%) was found in profile 4, the profile with the highest global AHI severity. Profiles 1 and 3 had similar proportions between men and women ( $43 \%$ and $51 \%$ women, respectively) $(\mathrm{p}<0.001)$ (Table 4).

Patients in profiles 2 and 4 had a lower prevalence of hypertension (40.4\% and $38.1 \%$, respectively) compared to profiles 1 and 3 ( $52 \%$ and $56 \%$, respectively) ( $\mathrm{p}=0.001$ ). Finally, strikingly, profile 4 had extremely low prevalence of COPD (7.9\%) compared to the other three profiles where prevalence was between $20.4 \%$ and $32.6 \%$ $\left(p=4.8 \times 10^{-6}\right)($ Table 4$)$.

\section{Discussion}

This observational study compared the clinical and qualitative PSG parameters between genders and described the presence of clinical profiles in a sample of patients with a diagnosis of OSA. The series of patients was obtained from a tertiary care hospital in Bogotá Colombia, a city located at high altitude, 2630 meters above sea level. The characteristic of the patients in this study made this group of patients different from that of previous reports analyzing the clinical variation between genders. In this study, most of the patients under PSG evaluation were hospitalized, were older, more obese while the proportion of males and females was similar.

The initial screening tool used to identify the risk of OSA was an abnormal Epworth Sleepiness Scale (ESS) 
Table 5 Continuous Variables Used in the Construction of the Profiles of Patients and Their Distribution Across Each Profile

\begin{tabular}{|c|c|c|c|c|c|}
\hline Variable & $\begin{array}{l}\text { Profile I Median } \\
\text { (IR) }\end{array}$ & $\begin{array}{l}\text { Profile } 2 \\
\text { Median (IR) }\end{array}$ & $\begin{array}{l}\text { Profile } 3 \text { Median } \\
\text { (IR) }\end{array}$ & $\begin{array}{l}\text { Profile } 4 \text { Median } \\
\text { (IR) }\end{array}$ & Adjust $\mathbf{P}$ \\
\hline Age & $66.5(61.25-76.75)$ & $60(52-70)$ & $66(58-73.75)$ & $61.5(55-70.75)$ & $0.0001 * *$ \\
\hline BMI & $30.85(27.28-32.8)$ & $30.2(25.3-34.2)$ & $31.1(26.3-37.1)$ & $31.8(27.53-36.65)$ & 0.0681 \\
\hline REM AHI (events/h) & $0(0-0)$ & $12(4-19.7)$ & $12(3-25.95)$ & $36.35(17.65-54.25)$ & $4.75 \times 10^{-38 * *}$ \\
\hline Supine AHI (events/h) & I $3.7(4.33-35.75)$ & $10(4.4-20.2)$ & $12.45(6.4-23.23)$ & $52(40-67.58)$ & $5.80 \times 10^{-41 * *}$ \\
\hline Total sleep time ( $\mathrm{min}$ ) & $362.5(316.75-570)$ & $496(419-577)$ & $360.5(290-427.75)$ & $382(336.5-459)$ & $9.63 \times 10^{-29 * *}$ \\
\hline N3 sleep (\%) & $2.5(0-10)$ & $6(2-10)$ & $3(0-9)$ & $3(0-7)$ & $0.0002 * *$ \\
\hline REM sleep $* *(\%)$ & $0(0-0)$ & $12(8-16)$ & $10(6-16)$ & $12(7-16)$ & $2.37 \times 10^{-27 * *}$ \\
\hline Sleep cycle (\%) & $0(0-0)$ & $(3-4)$ & $3(2-3)$ & $3(2-4)$ & $3.53 \times 10^{-39 * *}$ \\
\hline $\begin{array}{l}\text { Micro-awakenings during sleep associated } \\
\text { with respiratory events (events/h) }\end{array}$ & $10(6-18.5)$ & $8(3-16)$ & $8(4-18)$ & $38(8.25-61)$ & $7.87 \times 10^{-18 * *}$ \\
\hline Micro-awakenings during sleep (events/h) & $22(13.25-32)$ & $15(8-28)$ & $12(6-19)$ & $25(13-40)$ & $3.73 \times 10^{-13^{* *}}$ \\
\hline Periodic Limb Movements Index (events/h) & $0(0-1)$ & $0(0-1)$ & $I(0-I)$ & $0(0-2)$ & $5.05 \times 10^{-5 * *}$ \\
\hline Obstructive apnea (events) & I7.5(4.5-56.5) & $12(3-43)$ & II.5(3-25.75) & $46.5(14-148)$ & $5.11 \times 10^{-15^{* *}}$ \\
\hline Mixed apnea (events) & $0(0-2)$ & $0(0-2)$ & $0(0-1)$ & $5(0-17)$ & $3.42 \times 10^{-18^{* *}}$ \\
\hline Mean $\mathrm{SpO}_{2}(\%)$ & $83(72.25-88)$ & $86(81-89)$ & $86(8 I-89)$ & $85(80-88)$ & $0.0055 * *$ \\
\hline Sleep time with $\mathrm{SpO}_{2}<90 \%$ & $79.5(4 \mid-96)$ & $60(22-92)$ & $50(23-8 I)$ & $73.5(45-94)$ & $5.44 \mathrm{E} \times 10^{-5 * \text { *⿻一 }}$ \\
\hline
\end{tabular}

Note: Values are expressed as the median and interquartile range. $* *$ Statistical significant values $\mathrm{P}<0.05$.

score. The performance of ESS in our group of patients was $90.97 \%$, and the proportion of males was $49 \%$ and females $51 \%$. This is a high performance compared with other studies. In a study of a population with a similar ethnic background, the performance of ESS was close to $60 \%{ }^{37}$ The average ESS in the former study was 10.7 in males and 11.0 in females; in our sample of patients, the majority of the individuals had values higher than 9, indicating that the higher performance of ESS could be related to higher symptom severity in the group we studied and suggesting that our sample had a more severe OSA than other populations.

Likewise, our sample was older than the patients analyzed in several previous reports on OSA and gender. The previously mentioned study in Chilean patients had a mean age of 53.3 for male and 56.4 for female, ${ }^{37}$ while our patients were almost 10 years older in the male group and 5 years older in the female group. A study in a Caucasian population reported a mean age of 54 years in both genders; ${ }^{38}$ similarly, a report in patients from Cameroon found that the median age was 58 years. ${ }^{39}$

Additionally, the patients' BMI in this report was higher than most of the previous reports. While the mean BMI in our subjects was higher than 31 in both genders, other populations had a mean BMI lower than $30 .{ }^{19,22,38,39}$ Putting all these factors together, the group of patients described in this study were from a high-altitude city, in a developing country, and they were older and more obese than those in most of the previous reports.

In our series of patients, most of the demographic and clinical characteristics showed no differences between the genders; BMI and all the comorbidities except dyslipidemia had a similar distribution and prevalence in female and male. This agrees with other studies that did not report statistical differences in BMI between the genders. ${ }^{17,22,37,39}$ Interestingly, two cohorts with BMI differences between the genders (female having a higher BMI than male) were younger cohorts than ours. ${ }^{16,19}$

Regarding the lack of differences between genders in most of the comorbidities in our study, results in the literature are not consistent. Some reports find differences between genders in a single comorbidity, such as a higher prevalence of hypertension in female, ${ }^{39}$ or a greater prevalence of coronary artery disease in male. ${ }^{22}$ Other studies have found gender differences in several comorbidities. ${ }^{12,16,19}$ Studies with wider gender differences in comorbidities were those with the youngest population, while studies with older populations reported smaller differences. Our sample of patients is in the range of studies with older participants and supports the hypothesis that the older the studied patients, the fewer the differences in clinical variables, by gender. Despite the absence of important differences in comorbidities, like all the reports comparing severity by gender, we identified that OSA severity was greater in males than females. 
This study found that male had more severe PSG parameter alterations than female in almost all the sleep categories. Male had more total AHI and supine AHI events. Male recorded shorter and shallower phases of sleep with no eye movement and typical brain waves, compared to female who had deeper sleep and delta brain waves, with REM sleep associated with elevated brain activity. Female also had better sleep efficiency. Those results are similar to other studies that reported better sleep quality parameters in females, with more severe OSA parameters in males. ${ }^{22,40,41}$

Remarkably, the number of AHIs during REM showed no gender difference. This matches previous reports ${ }^{22}$ and strengthens the hypothesis that there are different mechanisms responsible for OSA during NREM and REM sleep. This also indicates the importance of using specific OSA measurements in the evaluation of the disease in women.

The median $\mathrm{SaO}_{2}$ was $86(80.75-89)$ for males and 86 (80-88) for females. This is a lower mean $\mathrm{SaO}_{2}$ than reported in several OSA studies, where the mean $\mathrm{SpO}_{2}$ was higher than 92 for both genders. ${ }^{37,39}$ This result can be explained by high altitude; two studies in Peru and Mexico, in cities with high altitude, reported that the mean $\mathrm{SpO}_{2}$ in patients with OSA was around $83 \%{ }^{42,43}$

Despite an increased severity of OSA in male compared with female, the mean $\mathrm{SpO}_{2}$ and the sleep time with $\mathrm{SpO}_{2}$ lower than $90 \%$ did not have statistically significant differences according to gender. Even so, a report from Cameroon found a lower mean $\mathrm{SpO}_{2}$ in female than male, ${ }^{39}$ suggesting that the long-term consequences of hypoventilation in OSA patients could be similar in both genders, even if the severity of the symptoms and PSG parameters are different.

To deepen our understanding of the behavior of OSA in our group of patients, we performed an unsupervised profile discovery analysis. In this way, we discovered the presence of clinical profiles within patients diagnosed with OSA. We found that 4 profiles best describe our sample: non-REM profile (Profile 1), normal sleep efficiency profile (Profile 2), abnormal sleep efficiency profile (Profile 3), and severe AHI profile (Profile 4).

The four profiles discovered had no statistically significant differences in BMI or most comorbidities. This contrasts with previous studies where these parameters are important for classifying patients with OSA. ${ }^{38,39}$ The group of patients reported here is older, hospitalized, and living in a high altitude. It is possible that these particular characteristics either individually or in combination may mask the importance of clinical variables in identifying profiles of OSA patients. This results go accordingly with the lack of important difference between the same parameters among genders in this sample of patients.

Accordingly, the variables characterizing each of the profiles were mainly polysomnography parameters. For example, global AHI presented a $\mathrm{p}=0.0001$ in our study and allows classifying the four groups according to the severity of global AHI, something also reported in similar studies. $^{24,25,44}$

Regarding Sa02, the participants in our study presented a higher risk of desaturation comparing to other studies. $^{25,26}$ The proportion of sleep-in which patients were under $90 \%$ saturation was higher in both the nonREM profile and the more severe profile, $79.5 \%$ of sleep and $73.5 \%$ of sleep, respectively. Mean $\mathrm{SpO}_{2}$ also presented statistically significant differences among the profiles. It is important in the following research to explore possible pathophysiologic explanations towards this finding. We propose a hypothesis of prolonged percentage of sleep with saturations below $90 \%$ could explain the inability of patients in the group to enter REM phase as an inhibitory mechanism to REM sleep. ${ }^{39}$ It is important to evaluate saturation in patients from high altitude because in a functional study of OSA patients at high altitude reported neurological changes compared to healthy voluntaries like a functional connectivity between posterior cingulate cortex, left caudate, and left thalamus, ${ }^{21}$ and those regions are involved in cingulo-opercular network which regulate task execution, if they are affected cognitive function may be affected. ${ }^{45}$

One of the most striking results was that in the severe AHI profile (Profile 4) a lower proportion of people with COPD was found. Only $8 \%$ of the patients in this profile had COPD compared to a proportion of $20 \%$ to $33 \%$ in the other profiles. This result is counterintuitive and not previously described. Although association between COPD and $\mathrm{OSA}^{46,47}$ is reported, it is to be expected that chronic lung disease is related to greater severity of OSA. The design of this study does not allow us to explore the causes of this inverse association between OSA severity and COPD prevalence. Due to the unique characteristics of the patients in this study, older age, and living in an altitude over 2630 meters, ${ }^{23-26,48,49}$ further research is needed. Different hypotheses can be tested to explain this result, for example, if COPD treatment could modulate the severity of OSA presentation at extreme altitude and at advanced age. 
An important limitation in this study is that symptoms associated with OSA were not assessed, while in other studies, important differences were associated with symptoms. For example, female reported depression, anxiety, morning headaches, and insomnia. ${ }^{14,37}$

\section{Conclusion}

We reported the first description of gender differences and profile analysis in a series of patients diagnosed with OSA living in a high-altitude city in a developing country. The patients we analyzed were more obese, older, and had lower $\mathrm{SpO}_{2}$ values than most of the populations previously reported. Despite the particularities of the sample, the polysomnographic gender differences were similar to what other publications have shown. An important finding of the gender analysis is that while male had a greater severity of polysomnographic OSA parameters than female, both genders had similar REM AHI, highlighting the importance of this parameter in the evaluation of OSA in female. More studies are necessary to evaluate this finding, especially in postmenopausal population in high altitude, because studies have evidenced that severity is higher after menopause. ${ }^{50}$

Regarding profiles discovery, in concordance with the gender analysis, we found that nor comorbidities or BMI were important in the generation of the profiles. In our group of patients, the profiles depended almost exclusively on polysomnographic measures. The profiles reflected mainly the severity of OSA, one profile with severely affected patients, other with patients without REM, and other two profiles of patients with less OSA severity and opposite efficiency of sleep.

\section{Disclosure}

The authors report no conflicts of interest in this work.

\section{References}

1. Solomon CG, Veasey SC, Rosen IM. Obstructive sleep apnea in adults. $N$ Engl J Med. 2019;380(15):1442-1449. doi:10.1056/NEJMcp181 6152

2. Franklin KA, Lindberg E. Obstructive sleep apnea is a common disorder in the population-A review on the epidemiology of sleep apnea. J Thorac Dis. 2015;7:1311-1322. doi:10.3978/j.issn.2072-1439.2015. 06.11

3. Mehra R. Sleep apnea and the heart.Cleveland Clinic J Med. 2019;86:10-18. doi:10.3949/ccjm.86.s1.03

4. Khayat R, Jarjoura D, Porter K, et al. Sleep disordered breathing and post-discharge mortality in patients with acute heart failure. European Heart Journal. 2015;36(23):1463-1469. doi:10.1093/eurheartj/ehu522
5. Collen J, Lettieri C, Wickwire E, Holley A. Obstructive sleep apnea and cardiovascular disease, a story of confounders! Sleep Breath. 2020;24(4):1299-1313. doi:10.1007/s11325-019-01945-w

6. Soin D, Kumar P, Chahal J, et al. Evaluation of obstructive sleep apnea in metabolic syndrome. J Fam Med Prim Care. 2019;8 (5):1580. doi:10.4103/jfmpc.jfmpc 17519

7. Subramanian A, Adderley NJ, Tracy A, et al. Risk of incident obstructive sleep apnea among patients with type 2 diabetes. Diabetes Care. 2019;42(5):954-963. doi:10.2337/dc18-2004

8. Stradling JR, Crosby JH. Predictors and prevalence of obstructive sleep apnoea and snoring in 1001 middle aged men. Thorax. 1991;46 (2):85-90. doi:10.1136/thx.46.2.85

9. Bixler EO, Vgontzas AN, Ten Have T. effects of age on sleep apnea in men i. prevalence and severity. Am J Respir Crit Care Med. 1998;157:144.

10. Joseph D'Ercole A, Ye P. Minireview: expanding the Mind: insulin-Like Growth Factor I and Brain Development. Endocrinology. 2008;149(12):5958-5962. doi:10.1210/en.2008-0920

11. Udwadia ZF, Doshi AV, Lonkar SG, Singh CI. Prevalence of sleep-disordered breathing and sleep apnea in middle-aged urban Indian men. Am J Respir Crit Care Med. 2004;169(2):168-173. doi:10.1164/rccm.200302-265OC

12. Basoglu OK, Tasbakan MS. Gender differences in clinical and polysomnographic features of obstructive sleep apnea: a clinical study of 2827 patients. Sleep Breath. 2018;22(1):241-249. doi:10.1007/ s11325-017-1482-9

13. Forcelini CM, Buligon CM, Kettenhuber Costa GJ, et al. Agedependent influence of gender on symptoms of obstructive sleep apnea in adults. Sleep Sci. 2019;12:132-137.

14. Hashim Z, Nath A, Gupta M, et al. Diagnosis of obstructive sleep apnea in women: is there any difference?- Experience from a tertiary care hospital of North India. J Fam Med Prim Care. 2019;8 (10):3276. doi:10.4103/jfmpc.jfmpc_609_19

15. Valipour A, Lothaller H, Rauscher H, Zwick H, Burghuber OC, Lavie P. Gender-related differences in symptoms of patients with suspected breathing disorders in sleep: a clinical population study using the sleep disorders questionnaire. Sleep. 2007;30(3):312-319. doi:10.1093/sleep/30.3.312

16. Gabbay IE, Lavie P. Age- and gender-related characteristics of obstructive sleep apnea. Sleep Breath. 2012;16(2):453-460. doi:10.1007/s11325-011-0523-z

17. Baldwin CM, Kapur VK, Holberg CJ, Rosen C, Nieto FJ. Associations between gender and measures of daytime somnolence in the Sleep Heart Health Study. Sleep. 2004;27(2):305-311. doi:10.1093/sleep/27.2.305

18. Ye L, Pien GW, Weaver TE. Gender differences in the clinical manifestation of obstructive sleep apnea. Sleep Med. 2009;10:1075-1084. doi:10.1016/j.sleep.2009.02.006

19. Pataka A, Kotoulas S, Kalamaras G, et al. Gender Differences in Obstructive Sleep Apnea: the Value of Sleep Questionnaires with a Separate Analysis of Cardiovascular Patients. J Clin Med. 2020;9 (1):130. doi:10.3390/jcm 9010130

20. Hermand E, Pichon A, Lhuissier FJ, Richalet J-P. Periodic breathing in healthy humans at exercise in hypoxia*. J Appl Physiol. 2015;118 (1):115-123. doi:10.1152/japplphysiol.00832.2014

21. Qin Z, Kang D, Feng X, Kong D, Wang F, Bao H. Resting-state functional magnetic resonance imaging of high altitude patients with obstructive sleep apnoea hypopnoea syndrome. Sci Rep. 2020;10(1):1.

22. Won CH, Reid M, Sofer T, et al. Sex Differences in Obstructive Sleep Apnea Phenotypes, the Multi-Ethnic Study of Atherosclerosis Christine. Sleep. 2019;43(5):zsz274.

23. Ye L, Pien GW, Ratcliffe SJ, et al. The different clinical faces of obstructive sleep apnoea: a cluster analysis. [Cited January 18, 2021]. Available from: www.statmodel.com. Accessed March 25, 2021.

24. Keenan BT, Kim J, Singh B, et al. Recognizable clinical subtypes of obstructive sleep apnea across international sleep centers: a cluster analysis. Sleep. 2018;41(3):zsx214. 
25. Zinchuk AV, Jeon S, Koo BB, et al. Polysomnographic phenotypes and their cardiovascular implications in obstructive sleep apnoea. Thorax. 2018;73(5):472-480. doi:10.1136/thoraxjnl-2017-210431

26. Vavougios GD, Natsios G, Pastaka C, Zarogiannis SG, Gourgoulianis KI. Phenotypes of comorbidity in OSAS patients: combining categorical principal component analysis with cluster analysis. J Sleep Res. 2016;25(1):31-38. doi:10.1111/jsr.12344

27. Bailly S, Destors M, Grillet Y, et al. Obstructive sleep apnea: a cluster analysis at time of diagnosis. PLoS One. 2016;11(6): e0157318.

28. Kendzerska TB, Smith PM, Brignardello-Petersen R, Leung RS, Tomlinson GA. Evaluation of the measurement properties of the Epworth sleepiness scale: a systematic review [Internet]. Sleep Med Rev. 2014;18(4):321-331. doi:10.1016/j.smrv.2013.08.002

29. Chiu HY, Chen PY, Chuang LP, et al. Diagnostic accuracy of the Berlin questionnaire, STOP-BANG, STOP, and Epworth sleepiness scale in detecting obstructive sleep apnea: a bivariate meta-analysis [Internet]. Sleep Med Rev. 2017;36:57-70. doi:10.1016/j. smrv.2016.10.004

30. Rundo JV, Downey R. Polysomnography. Handbook Clin Neurol. 2019;160:381-392.

31. Malhotra RK, Kirsch DB, Kristo DA, et al. Polysomnography for obstructive sleep apnea should include arousal-based scoring: an american academy of sleep medicine position statement. J Clin Sleep Med. 2018;14(7):1245-1247. doi:10.5664/jcsm.7234

32. Sateia MJ. International classifi cation of sleep disorders-th ird edition highlights and modifi cations. Chest. 2014;146:1387-1394. doi:10.1378/chest.14-0970

33. Ito $\mathrm{E}$, Inoue $\mathrm{Y}$. The international classification of sleep disorders, third edition. American Academy of Sleep Medicine. Includes bibliographies and index, Nihon Rinsho. Japanese $j$ Clin Med. 2015;73:916-923.

34. Lebart L, Morineau A. Statistique exploratoire multidimensionnelle fdi:010007837 - Horizon [Internet]; 1995. [Cited February 5, 2021]. Available from: https:/www.documentation.ird.fr/hor/fdi:010007837.

35. Benjamini Y, Hochberg Y. Controlling the false discovery rate: a practical and powerful approach to multiple testing. J R Stat Soc Ser B. 1995;57(1):289-300.

36. R: the R Project for Statistical Computing [Internet]. [Cited May 26, 2020]. Available from: https://www.r-project.org/. Accessed March 25, 2021.

37. Peñafiel FS, Rossel GS, Meza JC, et al. Gender differences in clinical features and performance of sleep questionnaires in adults with obstructive sleep apnea syndrome. Rev Med Chil. 2019;147 (10):1291-1302. doi:10.4067/s0034-98872019001001291

38. Fietze I, Laharnar N, Obst A, et al. Prevalence and association analysis of obstructive sleep apnea with gender and age differences results of SHIP-Trend. J Sleep Res. 2019;28(5):e12770. doi:10.1111/ jsr. 12770
39. Poka-Mayap V, Adamou DB, Massongo M, et al. Obstructive sleep apnea and hypopnea syndrome in patients admitted in a tertiary hospital in Cameroon: prevalence and associated factors. PLoS One. 2020;15(1):e0227778. doi:10.1371/journal.pone.0227778

40. Zhang Z, Cheng J, Yang W, Zou H, Su C, Miao J. Gender differences in clinical manifestations and polysomnographic findings in Chinese patients with obstructive sleep apnea. Sleep Breath. 2019;24 (3):1019-1026. doi:10.1007/s11325-019-01943-y

41. Earl DE, Lakhani SS, Loriaux DB, Spector AR. Predictors of moderate to severe obstructive sleep apnea: identification of sex differences. Sleep Breath. 2019;23(4):1151-1158. doi:10.1007/ s11325-019-01790-x

42. Pham LV, Meinzen C, Arias RS, et al. Cross-sectional comparison of sleep-disordered breathing in native Peruvian highlanders and lowlanders. High Alt Med Biol. 2017;18(1):11-19. doi:10.1089/ ham.2016.0102

43. Torre-Bouscoulet L, Castorena-Maldonado A, Baños-Flores R, Vázquez-García JC, Meza-Vargas MS, Pérez-Padilla R. Índice de desaturación de oxígeno frente a índice de apneas-hipopneas en adultos con sospecha de apnea obstructiva durante el sueño a $2.240 \mathrm{~m}$ de altitud. Arch Bronconeumol. 2007;43(12):649-654.

44. Ye L, Pien GW, Ratcliffe SJ, et al. The different clinical faces of obstructive sleep apnoea: a cluster analysis. Eur Respir J. 2014;44 (6):1600-1607. doi:10.1183/09031936.00032314

45. Dosenbach NUF, Fair DA, Cohen AL, Schlaggar BL, Petersen SE. A dual-networks architecture of top-down control. Trends Cogn Sci. 2008;12(3):99-105. doi:10.1016/j.tics.2008.01.001

46. Owens RL, Macrea MM, Teodorescu M. Invited review series: respiratory sleep disorders the overlaps of asthma or COPD with OSA: a focused review. Respirology. 2017;22(6):1073-1083.

47. Ioachimescu OC, Janocko NJ, Ciavatta M, Howard M, Warnock MV. Obstructive Lung Disease and Obstructive Sleep Apnea (OLDOSA) cohort study: 10-year assessment. J Clin Sleep Med. 2020;16 (2):267-277.

48. McNicholas WT, Hansson D, Schiza S, Grote L. Sleep in chronic respiratory disease: COPD and hypoventilation disorders [Internet]. Eur Respir Rev. 2019;28(153):190064. doi:10.1183/16000617.00642019

49. Lacedonia D, Carpagnano GE, Sabato R, et al. Characterization of obstructive sleep apnea-hypopnea syndrome (OSA) population by means of cluster analysis. J Sleep Res. 2016;25(6):724-730. doi: $10.1111 /$ jsr. 12429

50. Dancey DR, Hanly PJ, Soong C, Lee B, Hoffstein V. Impact of menopause on the prevalence and severity of sleep apnea. Chest. 2001;120(1):151-155. doi:10.1378/chest.120.1.151
Nature and Science of Sleep

\section{Publish your work in this journal}

Nature and Science of Sleep is an international, peer-reviewed, open access journal covering all aspects of sleep science and sleep medicine, including the neurophysiology and functions of sleep, the genetics of sleep, sleep and society, biological rhythms, dreaming, sleep disorders and therapy, and strategies to optimize healthy sleep.
The manuscript management system is completely online and includes a very quick and fair peer-review system, which is all easy to use. Visit http://www.dovepress.com/testimonials.php to read real quotes from published authors. 